\title{
The Effectiveness of Intravenous Golimumab Administered Directly After Infliximab in Rheumatoid Arthritis Patients
}

\author{
Vance J. Bray ${ }^{1} \cdot$ Aaron Broadwell $^{2} \cdot$ Herbert S. B. Baraf ${ }^{3} \cdot$ Shawn Black $^{5} \cdot$ Brenna L. Brady $^{4} \cdot$ Joseph Tkacz $^{4}$. \\ Lorraine Yarngo ${ }^{4} \cdot$ Raphael J. DeHoratius ${ }^{5,6}$
}

Published online: 28 July 2018

(c) The Author(s) 2018

\begin{abstract}
Purpose For patients with rheumatoid arthritis (RA) who do not respond or lose response to anti-tumor necrosis factor (TNF) biologics, switching to a different anti-TNF can be an effective means to manage symptoms and disease progression. This study examined the utilization and effectiveness of intravenous golimumab within a real-world population of patients with RA switching directly from infliximab, a potent anti-TNF.

Methods Patient charts $(n=113)$ were collected from five US-based rheumatology practices. Patient demographics, treatment characteristics, infliximab and intravenous golimumab utilization data, and Clinical Disease Activity Index (CDAI), Patient Global Assessment (PtGA), Physician Global Assessment (PhGA), and Routine Assessment of Patient Index Data (RAPID3) scores were extracted from charts. The effectiveness of intravenous golimumab was assessed by comparing disease activity status pre- and post-initiation of intravenous golimumab therapy.

Findings Significant decreases in patient disease activity were observed following treatment with intravenous golimumab. Mean CDAI and PhGA scores significantly decreased, and a significantly increased proportion of the population exhibited low disease activity or remission in the post intravenous golimumab period $(p<0.05)$. Limited changes were observed through the RAPID3 and PtGA.

Conclusions Findings from this study indicate that intravenous golimumab is effective in managing RA in a population of patients switching directly from infliximab (mean last dose $7.4 \mathrm{mg} / \mathrm{kg}$ ).
\end{abstract}

Shawn Black

sblack3@its.jnj.com

1 Denver Arthritis Clinic, 200 Spruce Street, Suite 100, Denver, CO 80230, USA

2 Rheumatology and Osteoporosis Specialists, 820 Jordan Street Suite 201, Shreveport, LA 71101-4616, USA

3 Arthritis and Rheumatism Associates, P.C, 2730 University Blvd West, Suite 306, Wheaton, MD 20902, USA

4 Health Analytics, LLC 9200 Rumsey Rd, Suite 215, Columbia, MD 21045, USA

5 Janssen Medical Affairs, 800 Ridgeview Dr, Horsham, PA 19044, USA

6 Sidney Kimmel School of Medicine, Thomas Jefferson University, Philadelphia, PA 19107, USA

\section{Key Points}

Intravenous golimumab is a highly effective anti-tumor necrosis factor (TNF) therapy for rheumatoid arthritis patients switching directly from infliximab.

This manuscript provides real-world evidence that rheumatoid arthritis patients switching from infliximab to intravenous golimumab have improved clinical outcomes.

\section{Introduction}

Rheumatoid arthritis (RA) is a chronic inflammatory autoimmune disease that affects approximately $1 \%$ of the population [1]. Traditionally, conventional disease-modifying antirheumatic drugs (cDMARDs) have been used to control inflammation associated with RA and manage disease. Although these agents have been shown to be effective in managing RA, some 
patients are unable to control their disease with cDMARDs alone. Biologic DMARDs (bDMARDs) have been shown to be effective in managing the symptoms of RA and are now considered the standard of care for treatment of patients with moderate to severe disease for whom cDMARDs have been unsuccessful [2,3].

Anti-tumor necrosis factor (TNF) biologics, which target the pro-inflammatory cytokine TNF- $\alpha$, are the largest class of biologic agents approved for the treatment of RA. Not all patients with RA respond to anti-TNF biologics [4], and estimates indicate that $30 \%$ of patients with RA experience primary non-response to their first anti-TNF biologic and another 30\% are secondary non-responders who lose response over time [4, 5]. Studies have shown that switching patients to a different anti-TNF biologic after non-response can be an effective use of bDMARDs. As a result, switching within the anti-TNF class is common, with approximately $50 \%$ of patients prescribed anti-TNF biologics switching between anti-TNF agents [4, 5]. Although response rates to biologics decline as the number of previous biologics increases, studies estimate that $35-62 \%$ of patients respond to their second anti-TNF, and approximately one-third of patients respond to their third anti-TNF [6-8].

Despite a wide array of anti-TNF agents available for the treatment of RA, only two agents are administered intravenously, limiting choices for patients and physicians who prefer the intravenous route of administration [9-11]. Studies have shown that patients with RA may prefer an intravenous route of administration for several reasons, including the safety of hospital administration, the presence of a doctor or other medical professional, convenience of treatment in a hospital, rapid onset of drug action, and reimbursement by Medicare $[12,13]$. Infliximab was first approved for RA in 1999 and was the first and only intravenous anti-TNF until the approval of intravenous golimumab in 2013. Due in part to its early availability and the general perception of its performance in the anti-TNF biologic market, infliximab remains one of the first-line biologic agents for the treatment of RA [10, 14]. Conversely, intravenous golimumab is more frequently used as a second-line anti-TNF therapy [15, 16]. The purpose of this retrospective chart review was to assess the safety and effectiveness of intravenous golimumab in patients with RA who recently discontinued intravenous infliximab therapy. Effectiveness was measured through changes in clinical outcome scores before and after treatment with intravenous golimumab.

\section{Methods}

\subsection{Study Design}

This study was a retrospective review of medical charts from patients with RA who switched from infliximab directly to intravenous golimumab. The review encompassed a maximum of an 8-year period during which patient outcomes and demographic, clinical, and utilization characteristic data were extracted. The measurement window extended from 5 years before the patient's switch to intravenous golimumab through the date of the chart review (performed June-October 2016). To facilitate the collection of patient data not present in the chart data, study sites were asked to complete a brief questionnaire for each chart to provide basic patient information (first visit at practice, date of first infliximab infusion). Rheumatologist practice information, including RA patient population, years in practice, and presence of an in-office infusion center were also collected to provide descriptive characteristics of the study sites.

\subsection{Study Sites}

Five rheumatologist practices located in the USA participated in the study by providing medical chart data. All five sites performed in-office infusions and were providing treatment to more than 100 patients with RA. Participating practices were required to complete contracting and training and to provide at least one eligible chart to be included in the study; all practices were paid a fee for completion of study start-up activities and per qualifying chart provided. Institutional Review Board approval with a waiver of consent and Health Insurance Portability and Accountability Act (HIPAA) authorization were obtained from the Chesapeake Institutional Review Board (Columbia, MD, USA) before providers were recruited and patient charts reviewed.

\subsection{Inclusion/Exclusion Criteria}

The following patient criteria were required of all patients to be included in the study:

1. Diagnosis of RA

2. Treatment with infliximab followed by a direct switch to intravenous golimumab

3. Aged $\geq 18$ years at the initiation of infliximab treatment

4. Absence of a primary diagnosis of psoriatic arthritis, plaque psoriasis, or ankylosing spondylitis.

Treatment with infliximab and intravenous golimumab was defined as a minimum of one infusion each. Patients were required to have switched directly from infliximab to intravenous golimumab and could not have received a different biologic agent between the two study medications; patients were permitted to have up to a 1-year period with no biologic utilization between treatment with infliximab and intravenous golimumab. 


\subsection{Data Collection}

Three sites transferred charts for data extraction, and the other two sites performed chart extraction onsite. Chart data were extracted into a Microsoft Access-based electronic case report form. Fields of interest included demographics, clinical RA details, RA medication utilization, dates and doses of infliximab and intravenous golimumab infusions, safetyrelated events, and outcome scales. Prior RA treatments were identified using both chart and provider questionnaire data.

Available chart data from 1 July 2008 through 27 October 2016 were included in the review. Data-extraction personnel were trained in the privacy laws and general research ethics of the HIPAA. All extracted data were reviewed by a single study coordinator who assessed data quality and ensured consistency in data collection across sites.

\subsection{Data Analysis-Demographics and Treatment Characteristics}

Demographically, frequencies and percentages were calculated for categorical variables of sex, ethnicity, disability status, and insurance type. Body mass index was calculated from patient height and weight. The frequency of comorbid conditions, prior RA surgeries, and prior RA treatments was evaluated, along with the mean length of treatment duration. Clinical disease activity assessments occurring within 90 days of intravenous golimumab initiation qualified as pre-period assessments, whereas the most recent assessment following intravenous golimumab initiation served as the post-period assessment.

\subsection{Data Logistics and Statistical Analyses}

The 90-day period preceding and including the day of intravenous golimumab treatment initiation constituted the "pre" period, and the disease activity assessment administered closest to and prior to intravenous golimumab initiation served as the baseline disease activity score. Following intravenous golimumab initiation, the most recent disease activity assessment on record while the patient was still receiving intravenous golimumab treatment served as the "post" period measure of disease activity for analysis of individual clinical outcome scales. Four clinical disease activity outcome scales were reported in charts: Clinical Disease Activity Index (CDAI), Patient Global Assessment (PtGA), Physician Global Assessment (PhGA), and Routine Assessment of Patient Index Data (RAPID3). For the CDAI, remission is considered achieved if a score is between 0 and 2.8. Low activity corresponds to $>2.8-10$ inclusive, moderate activity is between $>10$ and 22 inclusive, and high activity is strictly above 22 . The PhGA and PtGA are scored on a scale of $0-10$, with 0 being best and 10 being worst [17]. A score of $\leq 1.5$ corresponds to low disease activity for the PhGA, whereas a score of $\leq 2.0$ is considered low disease activity for the PtGA [17]. For the RAPID3, near remission is considered achieved if a score is 1 to 3. Low severity corresponds to a score of 4 to 6 . Moderate severity is a score of 7 to 12 inclusive, and high activity is indicated by a score of 13-30 [18]. Repeated-measures analyses were conducted on pre- and post-intravenous golimumab mean clinical scale scores. Four-level (remission, low, moderate, and high disease activity) and two-level (remission/low and moderate/high disease activity) categorical classifications were also assessed for the CDAI and RAPID3. Only twolevel (low or elevated disease activity) categorical classifications were evaluated for the PtGA and PhGA, consistent with the scoring of these clinical scales. Statistically significant differences in mean scores across each of the four scales were assessed via dependent $t$-tests. Significant differences in four-level ordinal clinical classifications from the CDAI and RAPID-3 were examined via Friedman's tests, and differences in two-level classification schemes were examined via McNemar's tests.

\subsection{Safety-Related Events}

Events that occurred within $24 \mathrm{~h}$ of an infliximab or intravenous golimumab infusion were classified as infusion reactions (IRs); all other events were categorized as adverse events (AEs). The number of reactions observed, as well as the proportion of patients reporting one or more event, were reported during both infliximab and intravenous golimumab treatment. Safety event rates were calculated by dividing the total events (AEs + IRs), AEs, or IRs by the total patient months specific to each therapy.

\section{Results}

\subsection{Intravenous Golimumab Effectiveness}

The overall sample of 113 charts primarily comprised females $(85.8 \%)$ and had a mean \pm standard deviation (SD) age of $61.2 \pm 15.6$ years (Table 1). Most patients transitioned to intravenous golimumab because of a loss of infliximab efficacy (Table 2). While clinical assessments of RA disease activity could be obtained from many patient charts, not all charts contained all disease activity measures of interest. Across the five sites, the most commonly collected disease activity assessments were the PtGA, PhGA, CDAI, and RAPID3. Patients with both pre-and post-intravenous golimumab CDAI $(n=22), \operatorname{PhGA}(n=25), \operatorname{PtGA}(n=39)$, or RAPID3 $(n=28)$ assessments were constructed as subsamples and served as the basis for the outcomes analyses. 
Table 1 Sample demographics

\begin{tabular}{|c|c|c|c|c|c|c|c|c|c|c|}
\hline & \multicolumn{2}{|c|}{$\begin{array}{l}\text { Full sample, } \\
n=113\end{array}$} & \multicolumn{2}{|c|}{ CDAI, $n=22$} & \multicolumn{2}{|c|}{ PhGA, $n=25$} & \multicolumn{2}{|c|}{ PtGA, $n=39$} & \multicolumn{2}{|c|}{$\begin{array}{l}\text { RAPID3, } \\
n=28\end{array}$} \\
\hline & Mean $/ f$ & $\mathrm{SD} / \%$ & $f$ & $\mathrm{SD} / \%$ & $f$ & $\mathrm{SD} / \%$ & $f$ & $\mathrm{SD} / \%$ & $f$ & $\mathrm{SD} / \%$ \\
\hline \multicolumn{11}{|l|}{ Sex } \\
\hline Female & 97 & $85.8 \%$ & 19 & $86.4 \%$ & 20 & $80.0 \%$ & 34 & $87.2 \%$ & 26 & $92.9 \%$ \\
\hline Mean age & 61.2 & 15.6 & 62.7 & 10.2 & 64.0 & 10.1 & 67.6 & 12.6 & 66.6 & 15.8 \\
\hline Mean disease duration ${ }^{\mathrm{a}}$ & 8.3 & 9.2 & 5.3 & 9.2 & 7.3 & 9.8 & 7 & 8.1 & 7.63 & 5.24 \\
\hline Mean BMI & 29.3 & 7.2 & 28.84 & 7.26 & 28.54 & 6.65 & 28.44 & 6.45 & 30.27 & 8.14 \\
\hline \multicolumn{11}{|l|}{ Ethnicity } \\
\hline Asian & 1 & $0.9 \%$ & 1 & $4.5 \%$ & 0 & $0.0 \%$ & 0 & $0.0 \%$ & 0 & $0.0 \%$ \\
\hline Black & 7 & $6.2 \%$ & 1 & $4.5 \%$ & 2 & $8.0 \%$ & 3 & $7.7 \%$ & 3 & $10.7 \%$ \\
\hline Latino & 7 & $6.2 \%$ & 2 & $9.1 \%$ & 0 & $0.0 \%$ & 0 & $0.0 \%$ & 2 & $7.1 \%$ \\
\hline Other & 1 & $0.9 \%$ & 0 & $0.0 \%$ & 0 & $0.0 \%$ & 0 & $0.0 \%$ & 0 & $0.0 \%$ \\
\hline White & 75 & $66.4 \%$ & 18 & $81.8 \%$ & 22 & $88.0 \%$ & 23 & $59.0 \%$ & 9 & $32.1 \%$ \\
\hline Pacific Islander & 1 & $0.9 \%$ & 0 & $0.0 \%$ & 0 & $0.0 \%$ & 0 & $0.0 \%$ & 0 & $0.0 \%$ \\
\hline Not reported & 21 & $18.6 \%$ & 0 & $0.0 \%$ & 1 & $4.0 \%$ & 13 & $33.3 \%$ & 14 & $50.0 \%$ \\
\hline \multicolumn{11}{|l|}{ Insurance type } \\
\hline Commercial & 50 & $44.2 \%$ & 10 & $45.5 \%$ & 11 & $44.0 \%$ & 9 & $23.1 \%$ & 7 & $25.0 \%$ \\
\hline Medicaid & 5 & $4.4 \%$ & 0 & $0.0 \%$ & 1 & $4.0 \%$ & 0 & $0.0 \%$ & 0 & $0.0 \%$ \\
\hline Medicare & 56 & $49.6 \%$ & 12 & $54.5 \%$ & 13 & $52.0 \%$ & 30 & $76.9 \%$ & 20 & $71.4 \%$ \\
\hline Other & 1 & $0.9 \%$ & 0 & $0.0 \%$ & 0 & $0.0 \%$ & 0 & $0.0 \%$ & 1 & $3.6 \%$ \\
\hline Unavailable & 1 & $0.9 \%$ & 0 & $0.0 \%$ & 0 & $0.0 \%$ & 0 & $0.0 \%$ & 0 & $0.0 \%$ \\
\hline
\end{tabular}

$B M I$ body mass index, $C D A I$ Clinical Disease Activity Index, $f$ frequency or frequency of observations, PhGA Physician Global Assessment, PtGA Patient Global Assessment, RAPID3 Routine Assessment of Patient Index Data, $S D$ standard deviation

Patient and Physician Global Assessments

${ }^{a}$ Disease duration based on the following samples: Full sample $n=85$; CDAI, $n=19$; PhGA, $n=19$; PtGA, $n=31 ;$ RAPID3, $n=19$

Table 2 Reasons for switching to intravenous golimumab treatment

\begin{tabular}{lr}
\hline Total & 61 \\
Reason for switch & $f$ \\
\hline Loss of efficacy & 52 \\
Patient preference & 2 \\
Insurance coverage & 7 \\
\hline$f$ frequency or frequency of \\
observations
\end{tabular}

The mean last dose of infliximab, received prior to the transition to intravenous golimumab, in all patients, and in patients from each of these disease activity assessment cohorts is shown in Table 3. The Remicade dose escalation, as evidenced by the final dose, was similar in each of the 4 cohorts. The mean treatment duration between pre- and postperiod CDAI and PhGA assessments was $445 \pm 278$ days and $439 \pm 282$ days, respectively. For patient-only measures such as the PtGA and RAPID3, the mean treatment duration between pre- and post-period assessments was $412 \pm 258$ days for the PtGA and $439 \pm 296$ days for the
RAPID3. Table 1 presents the demographic makeup of each of the four intravenous golimumab subsamples. Patients' non-biologic and biologic treatment history is shown in Tables 4 and 5, respectively.

\subsection{Intravenous Golimumab Effectiveness- Patient/Physician Measures}

The CDAI is a validated clinical instrument widely used to measure disease activity in RA and is calculated as the sum of four outcome parameters, which include a count of tender and swollen joints (0-28) and the patient and physician global assessment of disease activity. Using the CDAI to assess the study subsample cohort $(N=22)$, significant decreases were identified in the pre-period CDAI score mean of $21.6 \pm 12.3$ when compared with the post-period CDAI mean of $8.5 \pm 8.1$ (Fig. 1a and Table $6, p<0.05$ ). Two levels of clinical categorization of pre- and post-intravenous golimumab CDAI scores revealed a 50\% (81.8-31.8\%; $p<0.05)$ decrease in the number of patients with moderate/ high disease activity (Table 6). Significant decreases were also observed when categorized over four levels of disease 
A

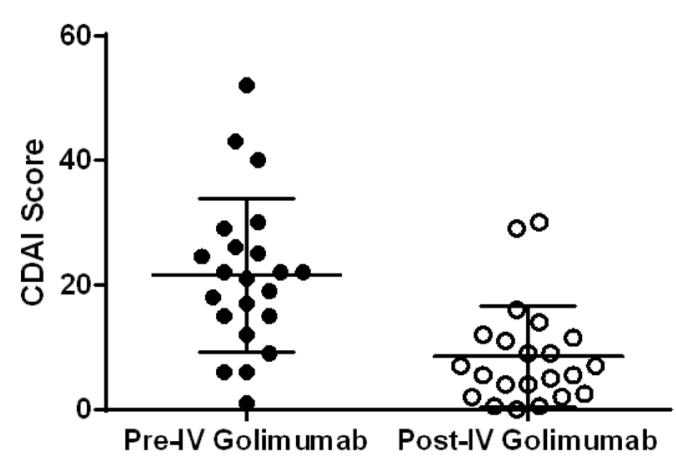

CDAl= Clinical Disease Assessment

PhGA $=$ Physician Global Assessment
B

PhGA

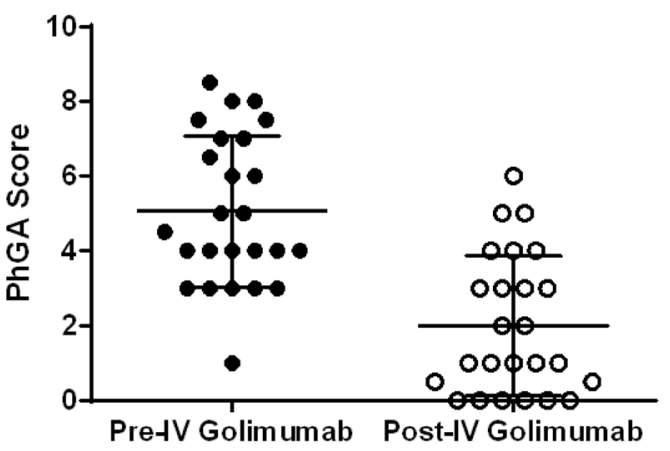

scores were the most recent score on record while the patient was receiving intravenous golimumab for rheumatoid arthritis. For each clinical score, centered bars represent the mean, and error bars represent the standard deviation. CDAI Clinical Disease Assessment, IV intravenous, PhGA Physician Global Assessment

RAPID3 were available pre- and post-treatment from 39 and 28 patient charts, respectively. The mean PtGA score decreased significantly from $5.8 \pm 2.3$ in the pre-period to $4.2 \pm 2.6$ in the post-period $(p<0.05)$. However, despite a significant decrease in the mean PtGA scores, no significant difference was observed in the proportion of patients changing from elevated to low disease activity over the course of the measurement window (Table 6). Evaluation of RAPID3 assessments demonstrated that the majority of patients evidenced no change in the level of disease activity following treatment with intravenous golimumab (Table 6).

\subsection{Safety Events}

Safety events were observed in $11.5 \%$ (13 of 113) of patient charts collected. Within the collected charts, 52 safetyrelated events (AEs or IRs) were identified over the measurement window of the chart review (5085.92 total patient months), which led to an overall rate of 102.2 safety events per 10,000 patient months (Fig. 2a, b). Most events (48 of 52 ) occurred during infliximab treatment (135.86 events

Table 3 Average final infliximab dose prior to golimumab therapy initiation

\begin{tabular}{|c|c|c|c|c|c|c|c|c|c|c|}
\hline & \multicolumn{2}{|c|}{$\begin{array}{l}\text { All Charts } \\
N=107\end{array}$} & \multicolumn{2}{|c|}{$\begin{array}{l}\text { CDAI } \\
N=22\end{array}$} & \multicolumn{2}{|c|}{$\begin{array}{l}\text { PtGA } \\
N=39\end{array}$} & \multicolumn{2}{|c|}{$\begin{array}{l}\text { PhGA } \\
N=25\end{array}$} & \multicolumn{2}{|c|}{$\begin{array}{l}\text { RAPID3 } \\
N=28\end{array}$} \\
\hline & Mean & SD & Mean & SD & Mean & $\mathrm{SD}$ & Mean & SD & Mean & $\mathrm{SD}$ \\
\hline $\begin{array}{l}\text { Final IFX dose } \\
\quad(\mathrm{mg} / \mathrm{kg})\end{array}$ & 7.41 & 2.094 & 7.166 & 2.02 & 6.32 & 2.5 & 7.71 & 1.84 & 5.9 & 2.74 \\
\hline
\end{tabular}


Table 4 Non-biologic treatment history

\begin{tabular}{lc}
\hline Non-biologic DMARD use $^{\mathrm{a}}$ & $\begin{array}{l}f(\%) \\
\text { Total, } n=113\end{array}$ \\
\hline Any non-biologic & $106(93.8)$ \\
Azathioprine & $12(10.6)$ \\
Hydroxychloroquine & $34(30.1)$ \\
Leflunomide & $40(35.4)$ \\
Methotrexate & $89(78.8)$ \\
Sulfasalazine & $9(8.0)$ \\
Any steroids & $88(77.9)$ \\
\hline
\end{tabular}

$D M A R D$ disease-modifying antirheumatic drug, $f$ frequency or frequency of observations

${ }^{a}$ Biologics other than the study medications (infliximab and intravenous golimumab only)

per 10,000 patient months), of which 39 of 52 were infliximab IRs (110.38 events per 10,000 patient months). Four patients reported nine AEs while on infliximab. All patients who had events while treated with intravenous golimumab (25.75 events per 10,000 patient months) had previously reported the same events (mouth ulcer and itching) while on infliximab. A total of 11 patients who had experienced safety events while previously treated with infliximab did not experience a safety event while treated with intravenous golimumab. Overall, no unexpected AEs were observed in the population while treated with either infliximab or intravenous golimumab.

\section{Discussion}

Biologic medications, and notably anti-TNF agents, have become the standard of care for patients with moderate to severe RA who are unable to control their disease with

Table 5 Biologic treatment history

\begin{tabular}{lc}
\hline Biologic DMARD use $^{\mathrm{a}}$ & $\begin{array}{l}f(\%) \\
\text { Total, } n=113\end{array}$ \\
\hline Any biologic & $50(44.2)$ \\
Tocilizumab & $22(19.5)$ \\
Certolizumab & $5(4.4)$ \\
Etanercept & $13(11.5)$ \\
Adalimumab & $17(15.0)$ \\
Abatacept & $21(18.6)$ \\
Rituximab & $15(13.3)$ \\
\hline
\end{tabular}

$D M A R D$ disease-modifying antirheumatic drug, $f$ frequency or frequency of observations

${ }^{a}$ Biologics other than the study medications (infliximab and intravenous golimumab only)
cDMARDs. The effectiveness of these agents has transformed the clinical management of RA [19]. Randomized clinical trials have shown that all currently available US FDA-approved anti-TNFs are effective in significantly reducing the clinical signs of inflammation in many patients with RA for whom cDMARDs have failed [19]. Despite this, discontinuation of an anti-TNF may occur for several reasons, including primary failure in some patients, loss of effectiveness and hypersensitivity, or IR. Regardless of the reason for discontinuation, transitioning to an effective therapy is necessary to prevent disease progression and loss of physical function that can lead to a lower health-related quality of life (HRQOL).

Despite the availability of multiple agents within the anti-TNF class, a limited number of agents are administered intravenously. This study focused on the effectiveness of intravenous golimumab within a real-world population of patients who switched directly to intravenous golimumab from infliximab therapy. Previous studies have underscored the clinical effectiveness of intravenous golimumab in patients with RA [20-22]. For example, the GO-FURTHER trial demonstrated that intravenous golimumab plus methotrexate caused significant inhibition of structural damage following administration at baseline, week 4 and every 8 weeks through 24 and 52 weeks $[21,23]$. The structural benefits of intravenous golimumab are also accompanied by improvements in many patient-reported measures of HRQOL, including improvements in the Health Assessment Questionnaire-Disability Index (HAQ-DI), 36-Item Short Form Health Survey (SF-36), EuroQoL 5-Dimensions (EQ-5D), EQ-5D visual analog scale (EQ5D-VAS), and Functional Assessment of Chronic Illness Therapy-Fatigue (FACITFatigue) instruments [22]. While these studies highlight the effectiveness of intravenous golimumab, they do so in bionaïve patients [21, 22]. Because intravenous golimumab is often used as a second-line therapy, this study provides the first outcome data from a clinically relevant sample of intravenous golimumab users who have switched directly from dose escalated infliximab, frequently with dose escalation.

The current study assessed the effectiveness of intravenous golimumab through several clinical outcome scales, including the CDAI, PhGA, PtGA, and RAPID3. Each of these scales measures slightly distinct aspects of disease activity [17]. Within the CDAI, PhGA, and PtGA subsample analyses, significant reductions in the levels of disease activity were observed following a switch to intravenous golimumab. Mean CDAI and PhGA scores decreased significantly, and a significantly increased proportion of the population exhibited low disease activity or remission after initiating intravenous golimumab $(p<0.05)$ (Table 6). Variability was observed across the four different clinical outcome scales. In general, reduction in disease severity following treatment with intravenous golimumab was more readily 
Table 6 Intravenous golimumab effectiveness by clinical scale

\begin{tabular}{|c|c|c|c|c|c|c|c|c|c|c|c|c|}
\hline & \multicolumn{3}{|l|}{ CDAI, $n=22$} & \multicolumn{3}{|c|}{ PhGA, $n=25$} & \multicolumn{3}{|c|}{ PtGA, $n=39$} & \multicolumn{3}{|c|}{ RAPID3, $n=28$} \\
\hline & Pre-GLM & $\begin{array}{l}\text { Post- } \\
\text { GLM }\end{array}$ & $\begin{array}{l}p \\
\text { value }^{\mathrm{a}}\end{array}$ & $\begin{array}{l}\text { Pre- } \\
\text { GLM }\end{array}$ & $\begin{array}{l}\text { Post- } \\
\text { GLM }\end{array}$ & $\begin{array}{l}p \\
\text { value }^{\mathrm{a}}\end{array}$ & $\begin{array}{l}\text { Pre- } \\
\text { GLM }\end{array}$ & $\begin{array}{l}\text { Post- } \\
\text { GLM }\end{array}$ & $\begin{array}{l}p \\
\text { value }^{\mathrm{a}}\end{array}$ & $\begin{array}{l}\text { Pre- } \\
\text { GLM }\end{array}$ & $\begin{array}{l}\text { Post- } \\
\text { GLM }\end{array}$ & $p$ value $^{\mathrm{a}}$ \\
\hline $\begin{array}{l}\text { Total mean score } \\
\text { 2-level classificatio }\end{array}$ & $21.6 \pm 12.3$ & $8.5 \pm 8.1$ & $<0.001$ & $5.1 \pm 2.0$ & $2 \pm 1.9$ & $<0.001$ & $5.8 \pm 2.3$ & $4.2 \pm 2.6$ & 0.002 & $14 \pm 5.3$ & $13.9 \pm 5.7$ & 0.913 \\
\hline Remission/low & $4(18.2)$ & $15(68.2)$ & 0.003 & $1(4.0)$ & $13(52.0)$ & 0.002 & $4(10.3)$ & $10(25.6)$ & 0.146 & $2(7.1)$ & $3(10.7)$ & 1 \\
\hline Moderate/high & $18(81.8)$ & $7(31.8)$ & & $24(96.0)$ & $12(48.0)$ & & $35(89.7)$ & $29(74.4)$ & & $26(92.9)$ & $25(89.3)$ & \\
\hline 4-level classificatio & & & & & & & & & & & & \\
\hline Remission & $1(4.5)$ & $6(27.3)$ & $<0.001$ & NA & & & NA & & & $2(7.1)$ & $2(7.1)$ & 0.48 \\
\hline Low & $3(13.6)$ & $9(40.9)$ & & & & & & & & $0(0.0)$ & $1(3.6)$ & \\
\hline Moderate & $10(45.5)$ & $5(22.7)$ & & & & & & & & $7(25.0)$ & $7(25.0)$ & \\
\hline High & $8(36.4)$ & $2(9.1)$ & & & & & & & & $19(67.9)$ & $18(64.3)$ & \\
\hline
\end{tabular}

Data are presented as mean \pm standard deviation or $f(\%)$

CDAI Clinical Disease Assessment, GLM golimumab, PhGA Physician Global Assessment, PtGA Patient Global Assessment

${ }^{\text {a }}$ Statistically significant differences between pre- and post-GLM on the clinical classification were assessed via McNemar $\chi^{2}$ test; differences in means were assessed via paired $t$ tests

observed in physician-reported scales, including the CDAI and $\mathrm{PhGA}$, than in the patient-reported outcome scales, although decreases in disease severity were also observed for the PtGA. There were no reductions in disease severity within the RAPID3 sample. All groups exhibited evidence of infliximab dose escalation $(\mathrm{mg} / \mathrm{kg}$ ) (Table 3 ) prior to initiation of intravenous golimumab therapy.

The literature indicates a generally high correlation between CDAI and RAPID3 measures for a given patient [18]; however, differences in patient outcomes observed with the RAPID3 and CDAI could be accounted for by disparities in patient level of disease severity across subsamples or the different aspects of RA symptomology being measured across the various scales. In our dataset, sites that collected CDAI scores as part of regular clinical practice collected relatively few RAPID3 scores, leading to these two subsamples being largely independent, whereas the CDAI, PhGA, and PtGA subsamples evidenced greater overlap. Patients within the CDAI and PhGA subsamples both demonstrated a significant decrease in clinical classification levels over the post period. These two subsamples also had the greatest overlap among any two scales, with 17 of the 22 CDAI patients having a PhGA and 17 of the $25 \mathrm{PhGA}$ patients also having a CDAI; further, the PhGA is a subcomponent of the CDAI composite score. The PtGA subsample also demonstrated a significant decrease in mean scores from the pre to post period, although there were no changes in patients' clinical categorical classification, diverging from the CDAI and PhGA subsamples. Like the PhGA, the PtGA is a component of the CDAI score but, unlike the PhGA, is patient reported, similar to the RAPID3. The two different perspectives of disease, physician versus patient, in conjunction with the differences in functional areas being assessed and rates of overlap between the subsamples, likely account for the disparity observed between the effectiveness of intravenous golimumab as measured through the RAPID3 and CDAI within this sample.

To date, no published studies have examined the efficacy of a transition from infliximab to intravenous golimumab, but transitions from infliximab to other biologic drugs have been studied. For example, Schiff et al. [24] published a study in which patients receiving abatacept or infliximab therapy for 12 months either continued on abatacept or switched from infliximab to abatacept. Patients were followed for an additional 12 months and, as a result of their treatment, only $77.8 \%$ of patients switching from infliximab to abatacept retained remission status, indicating that $\sim 22 \%$ of patients actually worsened to moderate or low disease activity following the transition to abatacept [24]. In contrast, our current results show the percentage of patients in remission increased by $22.8 \%$ ( $4.5 \%$ pre-golimumab to $27.3 \%$ post-golimumab) after transitioning from infliximab to intravenous golimumab (Table 6). A similar study found that only $14.4 \%$ of patients achieved remission when switched from infliximab to etanercept [25]. Finally, a study in which patients with RA switched to subcutaneous golimumab from their first TNF (adalimumab, etanercept, or infliximab) found that week 24 American College of Rheumatology improvement by $20 \%$ (ACR20) rates were 30.3, 46.8, and $50.9 \%$, for each biologic agent, respectively [26]. Similar trends for ACR20 rates were observed when discontinuation of the first biologic was taken into account [26].

In addition to examining the effectiveness of intravenous golimumab, we also explored the safety profile associated with the discontinuation of infliximab with a concomitant transition to intravenous golimumab. Overall, 52 safety events were reported within 13 patients, over a combined 5085.92 total patient months, resulting in an overall ratio 
A

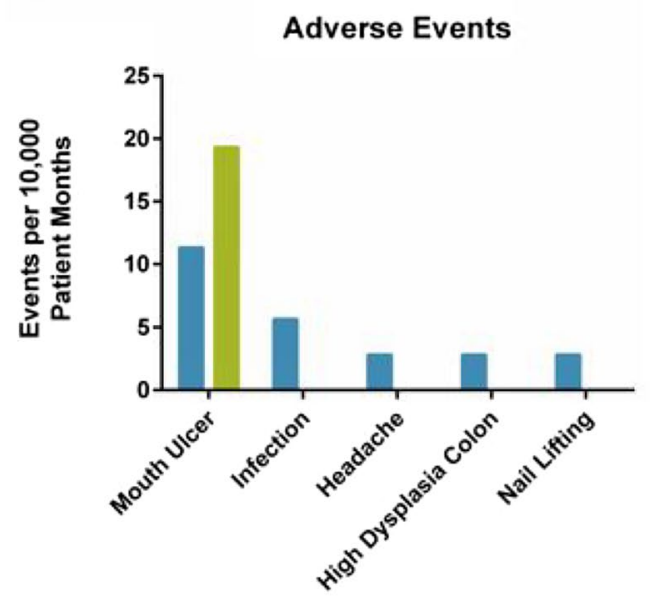

B

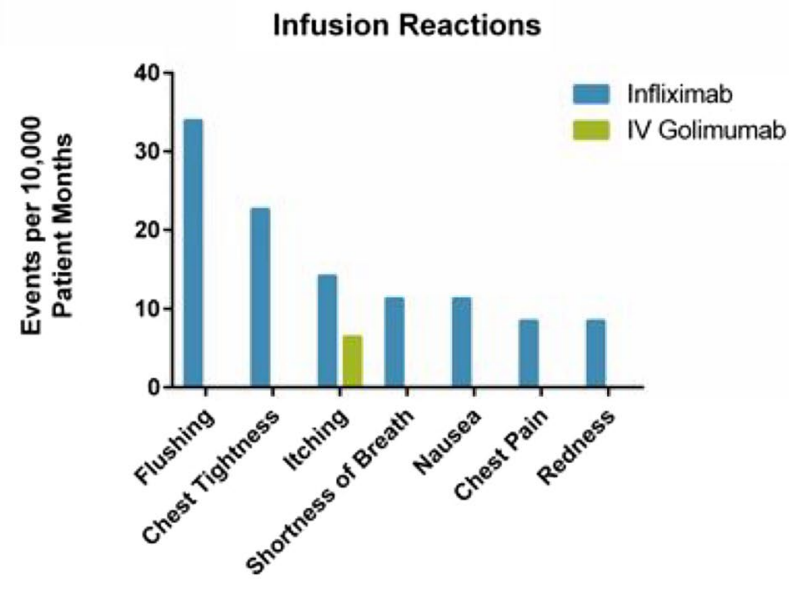

Fig. 2 Safety events and infusion reactions. Adverse events and infusion-related reactions are presented per 10,000 patient months for patients receiving infliximab (blue) or intravenous golimumab (green). Total patient months were 3533.03 for the infliximab patient population, 1552.89 for intravenous golimumab, and 5085.92 for overall patient population. There were 25.47 adverse events and 110.38 infusion-related reactions per 10,000 patient years for patients

of 102.2 safety events per 10,000 patient months. No unexpected or unusual AE patterns were noted.

This study has several limitations. The first is the inability to capture all details on all patients, which is commonplace for a retrospective real-world chart review. As such, it was not possible to segregate and analyze patient populations by other meaningful variables such as seropositivity status, or number of prior biologic therapies. Additionally, this study is limited by the lack of an equivalent comparison group for patients who switched from infliximab to intravenous golimumab since no other FDA-approved intravenous anti-TNF preparations are currently indicated for RA. While other intravenous (abatacept, rituximab, tocilizumab) and subcutaneous preparations do exist to treat RA, these therapies either exert other mechanisms of action or are administered subcutaneously and would not have been an appropriate comparison for patients preferring intravenous administration.

In summary, intravenous golimumab was shown to be effective in managing symptoms of RA based on clinical scale scores comparing periods before and after treatment. Results are especially meaningful given this particular sample of patients who developed moderate to severe disease despite receiving treatment with infliximab with dose escalation. The proportion of patients with moderate or severe disease was reduced following treatment with intravenous golimumab; decreases in clinical scale scores following intravenous golimumab treatment were also observed. while receiving infliximab. There were 19.31 adverse events and 6.43 infusion-related reactions per 10,000 patient years for patients while receiving intravenous golimumab. A single patient experienced all mouth ulcer-related AEs while treated with infliximab (four) and intravenous golimumab (three). In some cases, patients may have experienced more than one event while undergoing treatment

Funding Janssen Medical Affairs, LLC funded this study. The study sponsors contributed to the study design, interpretation of results, and manuscript development.

\section{Compliance with Ethical Standards}

Conflicts of interest SB is a current employee of Janssen Medical Affairs and stock holder in Johnson and Johnson. RJD is a former employee of Janssen Medical Affairs and current stock holder in Johnson and Johnson. VJB, AB, HSBB were site investigators and were compensated for charts provided as part of this study. BLB, JT, and LY were employed by Health Analytics, which was retained by Janssen to conduct this study.

Open Access This article is distributed under the terms of the Creative Commons Attribution-NonCommercial 4.0 International License (http://creativecommons.org/licenses/by-nc/4.0/), which permits any noncommercial use, distribution, and reproduction in any medium, provided you give appropriate credit to the original author(s) and the source, provide a link to the Creative Commons license, and indicate if changes were made.

\section{References}

1. Gibofsky A. Overview of epidemiology, pathophysiology, and diagnosis of rheumatoid arthritis. Am J Manag Care. 2012;18(13 Suppl):S295-302.

2. Scott DL. Biologics-based therapy for the treatment of rheumatoid arthritis. Clin Pharmacol Ther. 2012;91(1):30-43. https://doi. org/10.1038/clpt.2011.278.

3. Singh JA, Saag KG, Bridges SL Jr, Akl EA, Bannuru RR, Sullivan MC, et al. 2015 American college of rheumatology guideline 
for the treatment of rheumatoid arthritis. Arthritis Rheumatol. 2016;68(1):1-26. https://doi.org/10.1002/art.39480.

4. Emery P. Optimizing outcomes in patients with rheumatoid arthritis and an inadequate response to anti-TNF treatment. Rheumatology (Oxford). 2012;51(Suppl 5):v22-30. https://doi.org/10.1093/ rheumatology/kes 115 .

5. Hyrich KL, Lunt M, Watson KD, Symmons DP, Silman AJ. British Society for Rheumatology Biologics R. Outcomes after switching from one anti-tumor necrosis factor alpha agent to a second anti-tumor necrosis factor alpha agent in patients with rheumatoid arthritis: results from a large UK national cohort study. Arthritis Rheum. 2007;56(1):13-20. https://doi.org/10.1002/ art.22331.

6. Furst DE, Gaylis N, Bray V, Olech E, Yocum D, Ritter J, et al. Open-label, pilot protocol of patients with rheumatoid arthritis who switch to infliximab after an incomplete response to etanercept: the opposite study. Ann Rheum Dis. 2007;66(7):893-9. https ://doi.org/10.1136/ard.2006.068304.

7. Karlsson JA, Kristensen LE, Kapetanovic MC, Gulfe A, Saxne T, Geborek P. Treatment response to a second or third TNF-inhibitor in RA: results from the South Swedish Arthritis Treatment Group Register. Rheumatology (Oxford). 2008;47(4):507-13. https://doi. org/10.1093/rheumatology/ken034.

8. Rendas-Baum R, Wallenstein GV, Koncz T, Kosinski M, Yang $\mathrm{M}$, Bradley J, et al. Evaluating the efficacy of sequential biologic therapies for rheumatoid arthritis patients with an inadequate response to tumor necrosis factor-alpha inhibitors. Arthritis Res Ther. 2011;13(1):R25. https://doi.org/10.1186/ar3249.

9. Barton JL. Patient preferences and satisfaction in the treatment of rheumatoid arthritis with biologic therapy. Patient Prefer Adherence. 2009;3:335-44.

10. Greenapple R. Trends in biologic therapies for rheumatoid arthritis: results from a survey of payers and providers. Am Health Drug Benefits. 2012;5(2):83-92.

11. Scarpato S, Antivalle M, Favalli EG, Nacci F, Frigelli S, Bartoli $\mathrm{F}$, et al. Patient preferences in the choice of anti-TNF therapies in rheumatoid arthritis. Results from a questionnaire survey (RIVIERA study). Rheumatology (Oxford). 2010;49(2):289-94. https ://doi.org/10.1093/rheumatology/kep354.

12. Schwartzman S, Morgan GJ Jr. Does route of administration affect the outcome of TNF antagonist therapy? Arthritis Res Therapy. 2004;6(Suppl 2):S19-23. https://doi.org/10.1186/ar996.

13. Scarpato S, Antivalle M, Favalli EG, Nacci F, Frigelli S, Bartoli $\mathrm{F}$, et al. Patient preferences in the choice of anti-TNF therapies in rheumatoid arthritis. Results from a questionnaire survey (RIVIERA study). Rheumatology (Oxford, England). 2010;49(2):28994. https://doi.org/10.1093/rheumatology/kep354.

14. Curtis JR, Chastek B, Becker L, Quach C, Harrison DJ, Yun H, et al. Cost and effectiveness of biologics for rheumatoid arthritis in a commercially insured population. J Manag Care Spec Pharm. 2015;21(4):318-29. https://doi.org/10.18553/jmcp.2015.21.4.318.

15. Brady BL, Tkacz JP, Lofland J, Meyer R, Bolge SC. Prescribing patterns of intravenous golimumab for rheumatoid arthritis. Clin Ther. 2015;37(9):2028-36. https://doi.org/10.1016/j.clint hera.2015.06.017.

16. Tkacz J, Ellis L, Bolge SC, Meyer R, Brady BL, Ruetsch C. Utilization and adherence patterns of subcutaneously administered anti-tumor necrosis factor treatment among rheumatoid arthritis patients. Clin Ther. 2014;36(5):737-47. https://doi.org/10.1016/j. clinthera.2014.02.019.

17. Anderson JK, Zimmerman L, Caplan L, Michaud K. Measures of rheumatoid arthritis disease activity: Patient (PtGA) and Provider (PrGA) Global Assessment of Disease Activity, Disease Activity Score (DAS) and Disease Activity Score with 28-Joint Counts (DAS28), Simplified Disease Activity Index (SDAI), Clinical Disease Activity Index (CDAI), Patient Activity Score
(PAS) and Patient Activity Score-II (PASII), Routine Assessment of Patient Index Data (RAPID), Rheumatoid Arthritis Disease Activity Index (RADAI) and Rheumatoid Arthritis Disease Activity Index-5 (RADAI-5), Chronic Arthritis Systemic Index (CASI), Patient-Based Disease Activity Score With ESR (PDAS1) and Patient-Based Disease Activity Score without ESR (PDAS2), and Mean Overall Index for Rheumatoid Arthritis (MOI-RA). Arthritis Care Res (Hoboken). 2011;63(Suppl 11):S14-36. https://doi. org/10.1002/acr.20621.

18. Pincus T, Swearingen CJ, Bergman M, Yazici Y. RAPID3 (Routine Assessment of Patient Index Data 3), a rheumatoid arthritis index without formal joint counts for routine care: proposed severity categories compared to disease activity score and clinical disease activity index categories. The Journal of rheumatology. 2008;35(11):2136-47.

19. Agarwal SK. Biologic agents in rheumatoid arthritis: an update for managed care professionals. J Manag Care Pharm. 2011;17(9 Suppl B):S14-8. https://doi.org/10.18553/jmcp.2011.17.s9-b.s14.

20. Weinblatt ME, Bingham CO, Mendelsohn AM, Kim L, Mack M, $\mathrm{Lu} \mathrm{J}$, et al. Intravenous golimumab is effective in patients with active rheumatoid arthritis despite methotrexate therapy with responses as early as week 2: results of the phase 3, randomised, multicentre, double-blind, placebo-controlled GO-FURTHER trial. Ann Rheum Dis. 2013;72(3):381-9. https://doi.org/10.1136/ annrheumdis-2012-201411.

21. Weinblatt ME, Westhovens R, Mendelsohn AM, Kim L, Lo KH, Sheng S, et al. Radiographic benefit and maintenance of clinical benefit with intravenous golimumab therapy in patients with active rheumatoid arthritis despite methotrexate therapy: results up to 1 year of the phase 3 , randomised, multicentre, double blind, placebo controlled GO-FURTHER trial. Ann Rheum Dis. 2014;73(12):2152-9. https://doi.org/10.1136/annrheumdis-2013203742.

22. Bingham CO 3rd, Weinblatt M, Han C, Gathany TA, Kim L, Lo $\mathrm{KH}$, et al. The effect of intravenous golimumab on health-related quality of life in rheumatoid arthritis: 24-week results of the phase III GO-FURTHER trial. J Rheumatol. 2014;41(6):1067-76. https ://doi.org/10.3899/jrheum.130864.

23. Doyle MK, Rahman MU, Frederick B, Birbara CA, de Vries D, Toedter G, et al. Effects of subcutaneous and intravenous golimumab on inflammatory biomarkers in patients with rheumatoid arthritis: results of a phase 1, randomized, open-label trial. Rheumatology (Oxford, England). 2013;52(7):1214-9. https://doi. org/10.1093/rheumatology/kes381.

24. Schiff M, Keiserman M, Codding C, Songcharoen S, Berman A, Nayiager S, et al. Clinical response and tolerability to abatacept in patients with rheumatoid arthritis previously treated with infliximab or abatacept: open-label extension of the ATTEST Study. Ann Rheum Dis. 2011;70(11):2003-7. https://doi.org/10.1136/ annrheumdis-2011-200316.

25. Koike T, Harigai M, Inokuma S, Ishiguro N, Ryu J, Takeuchi T, et al. Safety and effectiveness of switching from infliximab to etanercept in patients with rheumatoid arthritis: results from a large Japanese postmarketing surveillance study. Rheumatol Int. 2012;32(6):1617-24. https://doi.org/10.1007/s00296-011-1807-0.

26. Smolen JS, Kay J, Matteson EL, Landewé R, Hsia EC, Xu S, et al. Insights into the efficacy of golimumab plus methotrexate in patients with active rheumatoid arthritis who discontinued prior anti-tumour necrosis factor therapy: post hoc analyses from the GO-AFTER study. Ann Rheum Dis. 2014;73(10):1811-8. https ://doi.org/10.1136/annrheumdis-2013-203435. 